\title{
Decomposing Mortality Rates and Examining Health Status of the Elderly in Jamaica
}

\author{
Paul A. Bourne ${ }^{*}, 1$, Donovan A. McGrowder ${ }^{2}$ and Tazhmoye V. Crawford ${ }^{3}$ \\ ${ }^{I}$ Department of Community Health and Psychiatry, Faculty of Medical Sciences, University of the West Indies, Mona \\ Campus, Kingston 7, Jamaica \\ ${ }^{2}$ Department of Pathology, Faculty of Medical Sciences, University of the West Indies, Mona Campus, Kingston 7, \\ Jamaica \\ ${ }^{3}$ Department of Basic Medical Sciences, Faculty of Medical Sciences, University of the West Indies, Mona Campus, \\ Kingston 7, Jamaica
}

\begin{abstract}
Population ageing in Jamaica follows a global trend where the number of persons aged 60 and over is increasing. This study investigated age-specific death rates, mortality sex ratio and health status of the elderly in Jamaica aged 55 years and over. The study utilized secondary data published by the Statistical Institute of Jamaica on mortality and secondary cross-sectional probability survey data were used to model poor health status in elderly residents. The findings revealed that there is increased life expectancy. In 2005, the age-specific mortality rate for elderly 75 years and older was 4.4 times more than that of the crude death rate for the population; 9.4 times more than that of age-specific death rate at ages 55 to 59 years and that disparity narrows at the elderly gets older. The mortality sex ratio revealed that between 115 to 120 males die for every 100 females. More men die between the ages of 55 and 75, than men 75 years and older. As Jamaicans become older than 55 years their poor health status significantly increased. Poor health status was accounted for significantly by hypertension, diabetes mellitus, and arthritis. Eight factors determine poor health status of elderly Jamaicans. Some of these factors are retirement income (OR = 1.461, 95\%CI:1.001, 2.131); cost of medical care $(\mathrm{OR}=1.144,95 \% \mathrm{CI}=1.073,1.220)$; area of residence (other towns $-\mathrm{OR}=0.754,95 \% \mathrm{CI}=0.597,0.953)$; marital status (separated - $\mathrm{OR}=1.901,95 \% \mathrm{CI}=1.479,2.445$; married $-\mathrm{OR}=1.406,95 \% \mathrm{CI}=1.103,1.792$ ); education (secondary $\mathrm{OR}=1.206,95 \% \mathrm{CI}=1.001,1.451$; tertiary level education $-\mathrm{OR}=0.492,95 \% \mathrm{CI}=0.281,0.861$ ), and number of men in household $(\mathrm{OR}=0.987,95 \% \mathrm{CI}=0.806,0.998)$. This study provides valuable information about the mortality rates and health status of elderly residents in Jamaica. High mortality rates for avoidable and preventable diseases and potential years of life lost are major public health concerns, especially for regional healthcare providers.
\end{abstract}

Keywords: Mortality, crude death rates, age-specific mortality rates, elderly, health, health status, Jamaica.

\section{INTRODUCTION}

Population ageing offers many challenges that impact on every dimension of life including family, economy, health services, education, and the general fabric of a society [1]. Many countries in the Caribbean have already begun to recognize the need to mainstream ageing into their comprehensive long-term development policies and programmes while others are re-examining already existing approaches to enhance welfare and well-being of not only their elderly but also to prepare the younger generations for their later years [2]. Birth cohorts of the elderly in Latin America and the Caribbean who reach age 60 years and above after 1990 are unique in that they are largely the product of medical interventions that increased childhood survival largely in the absence of significant improvements in standards of living. It is estimated that between 50 to 70 percent of the mortality decline that took place after 1945

*Address correspondence to this author at the Department of Community Health and Psychiatry, Faculty of Medical Sciences, The University of the West Indies, Mona, Jamaica; Tel: 876- 457-6990;

E-email: paulbourne1@yahoo.com was associated with medical interventions [3, 4]. The remaining decline was probably associated with better standards of living, increased knowledge about exposure and resistance to illnesses, and assorted other factors. Furthermore, a large fraction of these gains were concentrated early in the life of individuals, between birth and age five (5) or 10.

Worldwide life expectancy of the elderly is increasingly becoming higher for females than for their male counterparts. In developed countries, an average female life expectancy at birth of at least 80 years has become the norm. The average gap in life expectancy between the sexes is roughly seven (7) years in developed countries, but can be as great as 13 years in parts of the former Soviet Union as a result of unusually high levels [5]. Changes in overall life expectancy in developing regions of the world have been more uniform. Given the small average gender gap in life expectancy relative to developed nations, most demographers expect to see a widening of the female/male difference in upcoming decades, along the lines of the historical trend in industrialized nations [6]. One factor that may promote such a widening is education, which is 
positively related to survival. As women "catch up" to men in terms of educational attainment, we might expect to see relative improvements in survival and health status [7]. Greater male exposure to risk factors such as tobacco use, alcohol consumption, and occupational hazards often are cited as a source of higher male mortality rates than female [8].

The World Health Organization (WHO) in its World Health Report 2003 [9] states that population ageing and changes in the distribution of risk factors have accelerated the epidemic of non-communicable diseases in many developing countries. While non-communicable and lifestyle related diseases used to be the plight of the developed world, they are increasingly becoming major health threats for people in developing countries. Cardiovascular disease is by far the leading cause of death at older ages in developing countries, although the impact of communicable diseases remains considerable [10]. There is evidence that the prevalence of diabetes is highest in people over 65 years of age, with the highest incidence also occurring in this age group [11]. The burden of diabetes in the older population is set to increase even further because of demographic change, the rising incidence of diabetes in all age groups [12] and the longer survival of people who are diagnosed at a younger age [13]. Diabetes affects mortality and numerous studies have highlighted the reduced life expectancy associated with a diagnosis of diabetes [14], with mortality found to be almost 4-fold [15] and even as high as 9-fold [16] in older diabetics compared with non-diabetics.

In developed countries, the health and social status of the elderly has received a fair amount of attention [17]. With the Caribbean, some progress has been made in terms of research on the elderly since Braithwaite [18] when he noted that data on the Caribbean elderly were extremely limited. With the continuing aging of the population in the Caribbean, gerontological research has devoted increasing attention to those at very advanced ages [19] and in recent years, there has been increasing interest in issues relating to health of the elderly in the Caribbean. Patterns of mortality at the most advanced ages are of interest in their own right, indicating variation in health status and well-being among this group. Moreover, differences in mortality and trends in them may give clues about the likelihood of a further extension of life expectancy [20].

In Jamaica as is the same for most of the Caribbean, there are increasing numbers of persons living 60 years and some people are even living beyond the life expectancy of their perspective nations. Eldemire [21] noted that the elderly in Jamaica represents $10 \%$ of the population, and that they were for the most part mentally competent and physically independent. With a calculated life expectancy of 75.5 years [22], the burden on the healthcare system can be expected to increase. While we acknowledge the increasing longevity of the Jamaican population, many elderly have low socioeconomic status and continue to experience a number of other social as well as medical problems which influence their health status and can cause pre-mature mortality. For the last decade (1998-2007), statistics on mortality in Jamaica revealed that two-thirds of the annual deaths were people 60 years and older [23]. Given those issues and owing to the seemingly critical nature of mortality on ageing, this paper investigated life expectancy at birth of Jamaicans by gender, mortality sex ratios and age-specific mortality rates of adults 55 years and over. Aspects of the health status of these adults are investigated as well as chronic communicable and non-communicable diseases of persons with poor health status. The paper also examined factors which can predict poor health status in elderly persons (ages 55 years and older) in Jamaica.

\section{METHOD}

The current study utilized secondary data on mortality published by the Statistical Institute of Jamaica (STATIN). The data are collected by the Registrar General Department (RGD). The mortality data published by STATIN is a modification of the RGD's figures. This is in keeping with coverage errors identified by some scholars who examined the RGD's data on mortality.

There have been many postulations that RGD's data are not correctly reflecting a good coverage of deaths, and births in the country. This discourse has extended beyond demographers and epidemiologists in Jamaica to the United Nations. In keeping with the above-mentioned requisition from different scholars, STATIN have used the findings published in different studies $[24,25]$ as they found underregistration in fetal, infant and maternal deaths in the country [26]. In 1996, researchers revealed that the RGD data on deaths had an $84.8 \%$ coverage rate and 2 years later the figure raised to $89.6 \%$, which means a moderate coverage of data according to the World Health Organization - the ICD classification. It noted that $90 \%$ of completeness of death registration was said to be high quality data; and $70-89 \%$ was medium quality data [23]. Consequently, STATIN adjust RGD's mortality data to reflect $100 \%$ coverage.

This study employed the published data within STATIN's demographic statistics after the adjustment of the RGD's figure. The mortality data that were used in this study was on selected ages - ages 55 years and over. This research sought to decomposed mortality data at older ages in Jamaica in comparison to total deaths in a calendar year, examining any trends in mortality pattern in since 1998.

In addition to the aforementioned secondary data, crosssectional survey data were also utilized to examine health status and self-reported recurring (chronic) dysfunctions as diagnosed by a medical practitioner. The sub-sample for the current study was 3,748 persons (ages of 55 to 100 years) extracted from a nationally representative cross-sectional survey of 25,018 Jamaicans, the Jamaica Survey of Living Status (JSLC).

This study used JSLC 2002 which was conducted by STATIN and Planning Institute of Jamaica (PIOJ) between June and October 2002. The researchers selected this survey because it was the second largest sample size for the survey in its history (since 1988 to 1998), and in that year, the survey had questions on crime and victimization, and the physical environment unlike previous years. A selfadministered questionnaire was used to collect the data, which was stored and analyzed using SPSS for Windows 16.0. The questionnaire was modeled from the World Bank's Living Standards Measurement Study (LSMS) household survey. There were some modifications to the LSMS as JSLC was more focused on policy impacts. The 
questionnaire covered questions such as: socio-demographic, economic and wealth, crime and victimization, social welfare, health status and services, nutrition, housing, immunization of infants and physical environment. The nonresponse rate for the survey was $27.7 \%$. Hence, of the intended sample, $72.3 \%$ of the respondents answered the survey questions.

Descriptive statistics such as mean, standard deviation (SD), frequency and percentage were used to analyze the socio-demographic characteristics of the sample. Chi-square was used to examine association between non-metric variables; an Analysis of Variance (ANOVA) was used to evaluate the relationships between metric and nondichotomous categorical variables. To examine the predictors of poor health status, logistic regression was performed as the dependent variable was a binary one (selfreported health status, with 1 if good health status was reported and 0 if poor health).

Results were presented using un-standardized Bcoefficients, Wald statistics, odds ratio and confidence interval $(95 \% \mathrm{CI})$. The predictive power of the model was tested using Omnibus Test of Model and Hosmer and Lemeshow [27] was used to examine goodness of fit of the model. The correlation matrix was examined in order to ascertain whether autocorrelation (or multi-collinearity) existed between variables. Based on Cohen and Holliday [28], correlation can be low (weak), from 0 to 0.39 ; moderate, 0.4 to 0.69 , and strong, 0.7 to 1.0 . This was used to exclude (or allow) a variable in the model. Wald statistics was used to determine the magnitude (or contribution) of each statistically significant variables in comparison with the others, and the odds ratio (OR) for interpreting each significant variables.

\section{Measure}

Retirement income is a dummy variable where $1=$ having reported receiving public or private pensions, $0=$ otherwise. Durable goods index is the summation of all consumer goods owed by household members that are within the household. Average consumption expenditure is the total amount of money spent on consumption and non-consumption goods divided by the number of people in the household. Crowding is the total number of people in the household divided by the total number of rooms in the dwelling excluding verandah, kitchen and bathroom. Social class - this variable was measured based on income quintile. The upper classes were those in the wealthy quintiles (quintiles 4 and 5); middle class was quintile 3 and poor those in lower quintiles (quintiles 1 and 2). Poor health status (self-reported illness or self-reported dysfunction): The question was asked: "Is this a diagnosed recurring illness?" The answering options are: yes, cold; yes, diarrhoea; yes, asthma; yes, diabetes; yes, hypertension; yes, arthritis; yes, other; and no. A binary variable was later created from this construct $(1=$ yes, $0=$ otherwise) in order to use this in the logistic regression. Social supports represent different social networks with which the individual is involved $(1=$ membership of and/or visits to civic organizations or having friends who visit ones home or with whom one is able to network, $0=$ otherwise). Psychological conditions are the psychological state of an individual, and this is subdivided into positive and negative affective psychological conditions. Positive affective psychological condition is the number of responses with regard to being hopeful, optimistic about the future and life generally. Negative affective psychological condition is number of responses from a person on having lost a breadwinner and/or family member, having lost property, being made redundant, or failing to meet household and other obligations.

Crime Index $\mathrm{i}=\sum_{i=1}^{\mathrm{n}}\left(\mathrm{k}_{i} \mathrm{~T} \mathrm{j}\right)$

where ki represents the frequency with which an individual witnessed or experienced a crime, where i denote 0,1 and 2, in which 0 indicates not witnessing or experiencing a crime, 1 means witnessing 1 to 2 , and 2 symbolizes seeing 3 or more crimes. $\mathrm{Tj}$ denotes the degree of the different typologies of crime witnessed or experienced by an individual (where $\mathrm{j}=1 \ldots 4$, which 1 = valuables stolen, $2=$ attacked with or without a weapon, $3=$ threatened with a gun, and $4=$ sexually assaulted or raped. The summation of the frequency of crime by the degree of the incident ranges from 0 and a maximum of 51 .

\section{RESULTS}

The sample comprised of 3,748 respondents who were 55 years and older (48.2\% men and $51.8 \%$ women), with mean age being 68.87 years ( $\mathrm{SD}=9.67$ years). Approximately $8 \%$ of the sample had private health insurance compared to $92 \%$ who do not have private health insurance coverage. Twothirds of the sample resided in rural areas compared to $22 \%$ in peri-urban areas and $12 \%$ in urban areas. Marginally more of the respondents had social support (55\%); 19\% lived alone; $60 \%$ had at most primary level education; $4 \%$ had tertiary level education and $60 \%$ reported good health status. Forty-two percent of the sample was married; the median consumption per person per household was US\$551.96, and the mean number of visits to health care practitioners was $1.74(\mathrm{SD}=1.47)$. The mean crowding was 1.00 person $(\mathrm{SD}=$ 1.00 person). Thirty-seven percentage points of sample was poor, of which $18 \%$ were below the poverty line compared to $43 \%$ who were at least wealthy of which $23 \%$ were in the wealthiest social class (Table 1).

In 1998, 18.8 Jamaicans for every 1,000 Jamaicans died. Over a 9-year period (1998-2007), the crude death rate fell to 17.8 per 1,000 Jamaicans (Table 2). Although the crude death rates for Jamaicans ages 55 years and older fell for the same aforementioned period, it was 1.94 times more for older respondents than for the population in 1998 and the rate fell to 1.85 times in 2005 . Table 2 revealed that as Jamaicans age beyond 59 years, the age-specific death rate increases and this is significant for those 75 years and older. For Jamaicans 75 years and older, in 1998, the age-specific death rate was 7.8 times more than the age-specific death for ages 55 to 59 years, and the figure increased to 9.3 times in 2005. Since 1998 (to 2005), mortality at older age (75 years and over) has been fluctuating, with the only relatively stable period being from 1998 to 2001. However, there was a precipitous fall in 2004 over 1998 (by 13.0\%).

The age-specific death rates for the population and older ages do not provide a thorough understanding of the sex 
Table 1. Socio-Demographic Characteristic of the Respondents

\begin{tabular}{|c|c|c|}
\hline Details & \multicolumn{2}{|c|}{ n (\%) } \\
\hline \multicolumn{3}{|l|}{ Sex } \\
\hline Men & \multicolumn{2}{|c|}{$1,807(48.2)$} \\
\hline Women & \multicolumn{2}{|c|}{$1,941(51.8)$} \\
\hline \multicolumn{3}{|l|}{ Marital Status } \\
\hline Married & 1,558 & $(42.4)$ \\
\hline Never married & 1,148 & $(31.2)$ \\
\hline Divorced & 63 & $(1.7)$ \\
\hline Separated & 74 & $(2.0)$ \\
\hline Widowed & 834 & $(22.7)$ \\
\hline \multicolumn{3}{|l|}{ Per capita population income quintile } \\
\hline Poorest & 687 & $(18.3)$ \\
\hline Poor & 696 & $(18.6)$ \\
\hline Middle & 743 & $(19.8)$ \\
\hline Wealthy & 748 & $(20.0)$ \\
\hline Wealthiest & 874 & $(23.3)$ \\
\hline \multicolumn{3}{|l|}{ Good health status } \\
\hline No & 1,468 & $(39.8)$ \\
\hline Yes & 2,221 & $(60.2)$ \\
\hline \multicolumn{3}{|l|}{ Educational level } \\
\hline Primary and below & 2,122 & $(59.8)$ \\
\hline Secondary & 1,292 & $(36.4)$ \\
\hline Tertiary & 136 & $(3.8)$ \\
\hline \multicolumn{3}{|l|}{ Social support } \\
\hline No & 1,677 & $(44.7)$ \\
\hline Yes & 2,071 & $(55.3)$ \\
\hline \multicolumn{3}{|l|}{ Living Arrangement } \\
\hline With family or relative & \multicolumn{2}{|c|}{$3,035(81.0)$} \\
\hline Without family (alone) & 713 & $(19.0)$ \\
\hline \multicolumn{3}{|l|}{ Area of residence } \\
\hline Rural & 2,485 & $(66.3)$ \\
\hline Peri-Urban & 805 & $(21.5)$ \\
\hline Urban & 458 & $(12.2)$ \\
\hline \multicolumn{3}{|l|}{ Private Health Insurance Coverage } \\
\hline Not insured & \multicolumn{2}{|c|}{ 3,391 (92.4) } \\
\hline Insured & \multicolumn{2}{|c|}{$277(7.6)$} \\
\hline Age Mean (SD) & \multicolumn{2}{|c|}{68.87 years $(* .673)$} \\
\hline Consumption per person per household Median & \multicolumn{2}{|c|}{ US\$551.96* } \\
\hline Household Crowding Mean (SD) & \multicolumn{2}{|c|}{1.25 person $(0.96)$} \\
\hline Number of visits to made to health practitioners Mean (SD) & \multicolumn{2}{|c|}{$1.74(1.47)$} \\
\hline
\end{tabular}

* Rate in 2002 was US\$ $1=$ Ja.\$50.97.

disparity in mortality. The sex disparity in mortality is capture in life expectancy data (Table 3). In 1880-1882, life expectancy for females was 2.78 years more than that of males and 122 years later (2002-2004), the disparity has increased to 5.81 years. Once again this is for the population, and does not provide an understanding of mortality disparity at older ages for the sexes.

The mortality sex ratio revealed that between 115 to 120 males die for every 100 females. On decomposing these figures, it was revealed that more men die between the ages of 55 and 75, than men 75 years and older (Table 4). Of the mortality statistics at older ages, mortality sex ratio increased in ages 65 to 69 years $(7.62 \%)$ unlike any other old age cohorts (Fig. 1) for 2005 over 2004. Mortality sex ratio at older ages has been declining with the exception of the increase in the aforementioned age cohort. Consequently, the lowest reduction in mortality sex ratio was at ages 75 years and beyond $(2.58 \%)$. The largest decline was for ages 55 to 59 years $(5.95 \%)$ followed by $60-64$ years $(5.67 \%)$.

There was a negative correlation between good health status and age group of respondents $\left(\chi^{2}=171.799, \mathrm{p}=\right.$ $0.001)$. Table 5 revealed that while about $76 \%$ of Jamaicans aged 55 to 59 years reported good health status, this percentage decreased as the age of the respondents increased and averaged $48.3 \%$ of those aged 75 years and over. It was found that $32 \%$ of the sample reported that they were diagnosed with a chronic illness by a medical practitioner. Ninety-six percent of those who indicated that they had 
Table 2. Age-Specific Death Rates by Older Ages and Crude Death Rate, 1998-2007

\begin{tabular}{|c|c|c|c|c|c|c|c|c|c|c|}
\hline Ages & $\mathbf{1 9 9 8}$ & $\mathbf{1 9 9 9}$ & $\mathbf{2 0 0 0}$ & $\mathbf{2 0 0 1}$ & $\mathbf{2 0 0 2}$ & $\mathbf{2 0 0 3}$ & $\mathbf{2 0 0 4}$ & $\mathbf{2 0 0 5}$ & $\mathbf{2 0 0 6}$ & $\mathbf{2 0 0 7}$ \\
\hline \hline $\mathbf{5 5 - 5 9}$ & 10.8 & 11.4 & 10.6 & 10.8 & 10.1 & 9.3 & 8.6 & 8.3 & - & - \\
\hline $\mathbf{6 0 - 6 4}$ & 15.9 & 17.0 & 16.1 & 16.6 & 14.7 & 14.5 & 14.7 & 14.6 & - & - \\
\hline $\mathbf{6 5 - 6 9}$ & 23.7 & 25.3 & 23.8 & 24.5 & 20.6 & 19.4 & 19.3 & 18.5 & - & - \\
\hline $\mathbf{7 0 - 7 4}$ & 35.6 & 37.7 & 35.2 & 35.8 & 32.3 & 29.1 & 29.6 & 30.5 & - \\
\hline $\mathbf{7 5 +}$ & 84.3 & 88.8 & 83.0 & 84.6 & 75.9 & 76.6 & 73.8 & 77.6 & - \\
\hline${ }^{+} \mathbf{C D R}_{\mathbf{5 5}+}$ & 36.6 & 38.8 & 36.3 & 37.1 & 33.2 & 32.6 & 32.0 & 33.0 & - & - \\
\hline${ }^{\dagger+} \mathbf{C D R}_{\text {pop }}$ & 18.8 & 20.4 & 21.7 & 19.0 & 18.6 & 17.9 & 17.9 & 17.8 & 17.4 & 17.0 \\
\hline
\end{tabular}

${ }^{7} \mathrm{CDR}_{55+}$ denotes crude death rate for the population ages 55 years and older.

${ }^{\dagger} \mathrm{CDR}_{\text {pop }}$ this is crude death rate for the population ages 0 years and older.

Note: Computations of CDR55+ and the age-specific death rates (ASDRs) were done by Paul A. Bourne from Demographic Statistic, 2007 (Statistical Institute of Jamaica. Demographic Statistics, 2007. Kingston; STATIN; 2008:57).

chronic illness were diagnosed with this condition compared to $3.8 \%$ who claimed that their illness (chronic) was not diagnosed by a health practitioner. Most of the respondents who indicated being diagnosed with a chronic illness had hypertension $(37.6 \%)$ compared to $22.0 \%$ having diabetes mellitus, $15.3 \%$ having arthritis, $12.5 \%$ reported other and $2.7 \%$ reported asthma (Table 6 ). There was no statistical correlation between diagnosed chronic illness and age cohort of respondents $\left(\chi^{2}=24.46, p=0.657\right)$.

Table 3. Life Expectancy at Birth of Jamaicans by Sex: 18802004

\begin{tabular}{|c|c|c|}
\hline \multirow{2}{*}{ Period: } & \multicolumn{2}{|c|}{ Average Expected Years of Life at Birth } \\
\cline { 2 - 3 } & Male & Female \\
\hline \hline $1880-1882$ & 37.02 & 39.80 \\
\hline $1890-1892$ & 36.74 & 38.30 \\
\hline $1910-1912$ & 39.04 & 41.41 \\
\hline $1920-1922$ & 35.89 & 38.20 \\
\hline $1945-1947$ & 51.25 & 54.58 \\
\hline $1950-1952$ & 55.73 & 58.89 \\
\hline $1959-1961$ & 62.65 & 66.63 \\
\hline $1969-1970$ & 66.70 & 70.20 \\
\hline $1979-1981$ & 69.03 & 72.37 \\
\hline $1989-1991$ & 69.97 & 72.64 \\
\hline $1999-2001$ & 70.94 & 75.58 \\
\hline $2002-2004$ & 71.26 & 77.07 \\
\hline
\end{tabular}

Sources: Demographic Statistics (1972-2006).

In examining predictors of poor health status of elderly Jamaicans, eight factors were statistically associated with poor health status of elderly Jamaicans. The factors explain $10.6 \%$ of the variability in poor health of sample (Table 7). The model had a moderate statistical significant predictive power $(\chi 2=190.47, \mathrm{p}=0.001$; Hosmer and Lemeshow goodness of fit $\left.\chi^{2}=7.92, \mathrm{p}=0.441\right)$. Overall, $67.1 \%(\mathrm{n}=$ $1,580)$ of the data were correctly classified: $89.4 \%(\mathrm{n}=$ 1,338 ) indicated good health status and $28.1 \%$, poor health status $(n=242)$.
The factors that determine poor health status of elderly Jamaicans are retirement income $(\mathrm{OR}=1.461,95 \% \mathrm{CI}: 1.001$, $2.131)$; cost of medical care $(\mathrm{OR}=1.144,95 \% \mathrm{CI}=1.073$, 1.220 ); area of residence (other towns - OR $=0.754,95 \% \mathrm{CI}$ $=0.597,0.953$ ); marital status (separated - OR $=1.901$, $95 \% \mathrm{CI}=1.479,2.445 ;$ married $-\mathrm{OR}=1.406,95 \% \mathrm{CI}=$ $1.103,1.792$ ); education (secondary - $\mathrm{OR}=1.206,95 \% \mathrm{CI}=$ $1.001,1.451$; tertiary level education $-\mathrm{OR}=0.492,95 \% \mathrm{CI}=$ $0.281,0.861$ ); psychological conditions (negative affective condition $-\mathrm{OR}=1.035,95 \% \mathrm{CI}=1.004,1.068$; positive affective condition $-\mathrm{OR}=0.945,95 \% \mathrm{CI}=0.909,0.983)$; number of men in household $(\mathrm{OR}=0.987,95 \% \mathrm{CI}=0.806$, $0.998)$, and durable goods $(\mathrm{OR}=0.953,95 \% \mathrm{CI}=0.914$, 0.994; Table 7).

\section{DISCUSSION}

Life expectancy between 1880 and 2004 clearly indicates a gradual upward progression and that the disparity of lived years between the sexes was greatest for 2002 to 2004 . Females continue to have a higher life expectancy than males and the gap between the life expectancy of males and females widened from 2.78 years in $1880-1884$ to 5.81 years in 2002-2004. This indicates that while the Jamaican population is ageing, on an average mortality for women is falling compared to men. A study carried out in 1995, showed that there were 110,430 males and 130,020 females in Jamaica in the 60 years and older group, representing $9.42 \%$ of the population [29]. Another study reported that in the years $1996-1998$, and 2002-2004, there was a significant increase in life expectancy and in the average life span of the country's population [30]. Furthermore, it was also found that Jamaican males born in the earlier period (1996-1998), can expect to live 69.98 years, and females can look forward to live 75.58 years. Jamaican males born in 2002-2004 can expect to live 71.26 years compared with their female counterpart who can look forward to 77.07 years [30]. The positive trend in life expectancy is indicating that the proportion of the elderly in the Jamaican population is increasing. The increase in life expectancy can be explained by: increase in the number of births, reduction in infant mortality, decrease in premature deaths, decrease in mortality rate, the elimination of most infectious diseases and improved health care [31]. The gains reported in recent 


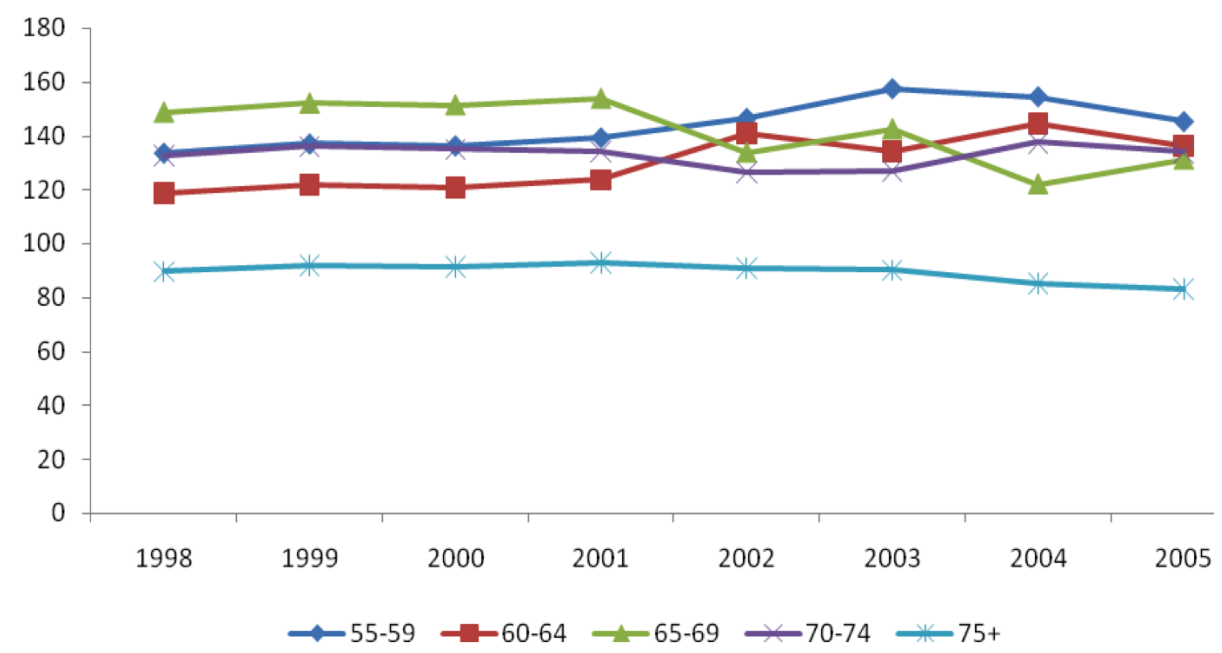

Fig. (1). Mortality of sex ratio by older ages and population, 1998-2006.

Table 4. Mortality Sex Ratio by Older Ages and Population, 1998-2006

\begin{tabular}{|c|c|c|c|c|c|c|c|c|}
\hline Ages & $\mathbf{1 9 9 8}$ & $\mathbf{1 9 9 9}$ & $\mathbf{2 0 0 0}$ & $\mathbf{2 0 0 1}$ & $\mathbf{2 0 0 2}$ & $\mathbf{2 0 0 3}$ & $\mathbf{2 0 0 4}$ & $\mathbf{2 0 0 5}$ \\
\hline \hline $55-59$ & 133.7 & 137.1 & 136.4 & 139.4 & 146.6 & 157.6 & 154.6 & 145.4 \\
\hline $60-64$ & 118.8 & 121.8 & 121.1 & 123.8 & 140.9 & 134.3 & 144.6 & 136.4 \\
\hline $65-69$ & 148.8 & 152.2 & 151.5 & 153.9 & 133.8 & 142.6 & 122.0 & 131.3 \\
\hline $70-74$ & 132.7 & 136.1 & 135.1 & 134.3 & 126.5 & 127.2 & 137.6 & 134.0 \\
\hline $75+$ & 89.7 & 91.9 & 91.3 & 93.1 & 90.9 & 90.2 & 85.2 & 83.0 \\
\hline Population & 115.3 & 117.9 & 117.3 & 119.5 & 118.6 & 118.2 & 119.7 & 117.3 \\
\hline
\end{tabular}

Table 5. Health Status by Age Group

\begin{tabular}{|c|c|c|c|c|c|c|}
\hline \multirow{2}{*}{ Health Status } & \multicolumn{5}{|c|}{ Age Cohort } & \multirow{2}{*}{$\begin{array}{c}\text { Total } \\
\text { n (\%) }\end{array}$} \\
\hline & $\begin{array}{l}55-59 \\
\text { n (\%) }\end{array}$ & $\begin{array}{l}60-64 \\
\text { n (\%) }\end{array}$ & $\begin{array}{l}65-69 \\
\text { n (\%) }\end{array}$ & $\begin{array}{l}70-74 \\
\text { n (\%) }\end{array}$ & $\begin{array}{c}75+ \\
\text { n (\%) }\end{array}$ & \\
\hline Poor & $178(24.5)$ & $226(33.2)$ & $234(36.1)$ & $287(49.4)$ & $543(51.7)$ & $101468(39.8)$ \\
\hline Good & $550(75.5)$ & $455(66.8)$ & $414(63.9)$ & $294(50.6)$ & $508(48.3)$ & $2221(60.2)$ \\
\hline Total & 728 & 681 & 648 & 581 & 1051 & 3689 \\
\hline
\end{tabular}

$\mathrm{X}^{2}=171.799, \mathrm{p}=0.001, \mathrm{cc}=0.211$.

Table 6. Diagnosed (Chronic) Illness by Age Cohort

\begin{tabular}{|c|c|c|c|c|c|c|}
\hline \multirow[b]{2}{*}{$\begin{array}{l}\text { Chronic } \\
\text { Illness }\end{array}$} & \multicolumn{5}{|c|}{ Age Cohort } & \multirow{2}{*}{$\begin{array}{l}\text { Total } \\
\text { n (\%) }\end{array}$} \\
\hline & $\begin{array}{c}\text { Pre Elderly } \\
\text { (Ages } 55 \text { to } 59 \text { Years) } \\
\text { n (\%) }\end{array}$ & $\begin{array}{c}\text { Elderly } \\
\text { (Ages } 60 \text { to } 64 \text { Years) } \\
\text { n (\%) }\end{array}$ & $\begin{array}{c}\text { Elderly } \\
\text { (Ages } 65 \text { to } 69 \text { Years) } \\
\text { n (\%) }\end{array}$ & $\begin{array}{c}\text { Elderly } \\
\text { (Ages } 70 \text { to } 74 \text { Years) } \\
\text { n (\%) }\end{array}$ & $\begin{array}{c}\text { Elderly } \\
\text { (Ages 75+ Years) } \\
\mathbf{n}(\%)\end{array}$ & \\
\hline Cold & $8(5.8)$ & $14(7.4)$ & $10(5.2)$ & $10(4.3)$ & $16(3.6)$ & $58(4.9)$ \\
\hline Diarrhoea & $1(.7)$ & $2(1.1)$ & $2(1.0)$ & $5(2.1)$ & $7(1.6)$ & $17(1.4)$ \\
\hline Asthma & $3(2.2)$ & $5(2.7)$ & $1(.5)$ & $8(3.4)$ & $15(3.4)$ & $32(2.7)$ \\
\hline Diabetes & $33(24.1)$ & $42(22.3)$ & $35(18.2)$ & $55(23.5)$ & $97(21.9)$ & $262(22.0)$ \\
\hline Hypertension & $55(40.1)$ & $72(38.3)$ & $77(40.1)$ & $79(33.8)$ & $165(37.3)$ & $448(37.6)$ \\
\hline Arthritis & $16(11.7)$ & $23(12.2)$ & $30(15.6)$ & $40(17.1)$ & $73(16.5)$ & $182(15.3)$ \\
\hline Other & $12(8.8)$ & $22(11.7)$ & $29(15.1)$ & $30(12.8)$ & $56(12.7)$ & $149(12.5)$ \\
\hline No & $9(6.6)$ & $8(4.3)$ & $8(4.2)$ & $7(3.0)$ & $13(2.9)$ & $45(3.8)$ \\
\hline Total & 137 & 188 & 192 & 234 & 442 & 1193 \\
\hline
\end{tabular}


years in mean life expectancy at various age groups has no doubt contributed to the common view that major breakthroughs in medicine that reduce deaths from the major chronic diseases will now produce significant reductions in mortality of older persons and consequent prolongation in life expectancy. Improvements in healthcare and increased accessibility to healthcare equally play a role in the increased life expectancy [32] as well as sanitation, good quality water and better nutritional intake of foods by people.
Other supporting studies carried out in the Caribbean show that persons at age 60 can expect to live another 20 years, with the highest value for Barbadian and Cuban women (22.5 years) and the lowest value for men from Haiti and Guyana (less than 16 years additional years) [33]. In terms of health-adjusted life expectancy rates, a person at age 60 in the Caribbean should be able to spend on the average two thirds of his/her life expectancy in good health [33]. Furthermore, the difference between life expectancy at birth for men and women in the Caribbean is presently 5.5

Table 7. Poor Health Status of Elderly Jamaicans by Some Explanatory Variables

\begin{tabular}{|c|c|c|c|c|c|}
\hline private health insurance & -0.159 & 0.193 & 0.685 & 0.853 & $0.584-1.244$ \\
\hline two wealthiest quintile & 0.118 & 0.138 & 0.725 & 1.125 & $0.858-1.476$ \\
\hline †poor dummy retirement income & 0.379 & 0.193 & $3.868^{*}$ & 1.461 & $1.001-2.131$ \\
\hline medical expenditure & 0.135 & 0.033 & $16.898 * * *$ & 1.144 & $1.073-1.220$ \\
\hline average consumption & 0.000 & 0.000 & 0.082 & 1.000 & $1.000-1.000$ \\
\hline house tenure - rent & -0.827 & 1.892 & 0.191 & 0.437 & $0.011-17.824$ \\
\hline house tenure - owned & -1.509 & 1.224 & 1.521 & 0.221 & $0.020-2.433$ \\
\hline separated, divorced, or widowed & 0.643 & 0.128 & $25.094 * * *$ & 1.901 & $1.479-2.445$ \\
\hline married & 0.341 & 0.124 & $7.587 * *$ & 1.406 & $1.103-1.792$ \\
\hline$\dagger$ single secondary & 0.187 & 0.095 & $3.899 *$ & 1.206 & $1.001-1.451$ \\
\hline tertiary & -0.709 & 0.285 & $6.183 *$ & 0.492 & $0.281-0.861$ \\
\hline$\dagger$ primary social support & 0.155 & 0.092 & 2.839 & 1.167 & $0.975-1.398$ \\
\hline living arrangement & -0.264 & 0.158 & 2.790 & 0.768 & $0.563-1.047$ \\
\hline sex & -0.553 & 0.101 & $30.061 * *$ & 0.575 & $0.472-0.701$ \\
\hline crowding & -0.082 & 0.080 & 1.043 & 0.921 & $0.787-1.078$ \\
\hline number of women & -0.053 & 0.058 & 0.853 & 0.948 & $0.847-1.062$ \\
\hline number of child & -0.071 & 0.048 & 2.213 & 0.932 & $0.849-1.023$ \\
\hline durable goods index & -0.048 & 0.021 & $5.045^{*}$ & 0.953 & $0.914-0.994$ \\
\hline constant & 1.113 & 1.365 & 0.665 & 3.043 & \\
\hline
\end{tabular}

Nagelkerke R-square $=10.6 \%$.

-2 Log likelihood $=2,901.81$.

Hosmer and Lemeshow $\chi^{2}=7.92 ; \mathrm{P}=0.441$.

Model: Omnibus Test $-\chi^{2}=190.47, \mathrm{p}=0.001$.

Overall correct classification $=67.1 \%(n=1,580)$

Correct classification of cases of poor health status $=28.1 \%(n=242)$.

Correct classification of cases of good health status $=89.4 \%(\mathrm{n}=1,338)$;

${ }^{*} \mathrm{p}<0.05, * * \mathrm{p}<0.01, * * * \mathrm{p}<0.001$.

$\dagger$ Reference group. 
years, but the gap appears to narrow with increasing age, with a difference of 2.5 years at age 60 and less than one year at age 80 [33]. A possible explanation for these genderspecific differences in life expectancy could be the fact that women seem to be generally more health conscious than men and consequently consult medical professionals more frequently than men.

The results of this study showed that the mortality sex ratio of the elderly fluctuates in the various age groups although it increases from 1998 to 2004 in the 55 to 59 age group and decreases in the 65 to 69 age group. Overall, most of the years showed a marginal increase in the mortality sex ratio in the population, and there was a significant decrease in the 75 years and over group compared with the $70-74$ age group. This suggests that the mortality rate of females relative to males increased significantly in the 75 years and over. This emphasized that the death rates themselves are higher for males as for females at the same ages and this differential is slightly increasing possibly as a result of increased in the mortality rates for females 75 years and over.

There is evidence suggesting that self-reported health is an indicator of general health with good construct validity [34] and is a respectably powerful predictor of mortality risks [35], disability [36] and morbidity [37], though these properties vary somewhat with national or cultural contexts [35]. The results of this study showed that the majority of those sampled reported themselves to be experiencing fair to good health, with thirty seven percent reporting bad health. Another key observation is that with increasing age of the respondents, less reported good heath suggesting that the elderly becomes older, there is decreased health status. These results compare very favourably with results coming out of Dominica [38] and Trinidad [39]. In reviews of the literature, Benyamini \& Idler [40] and Idler \& Benyamini [35], showed that in most studies conducted since the 1980s, the elderly people who self-rated their health as bad presented greater incidence of death than did those who considered it to be excellent. Among elderly people, self-rated health may present greater sensitivity for men than for women. Since women live longer than men and experience more years with diseases and incapacities, they tend to rate their health more negatively than do men, but do not necessarily die because of this, over the short term. Thus, negative self-rated health expressed by women may be more associated with quality of life. On the other hand, when men rate their health negatively, they present a greater risk of succumbing to a fatal event [41]. This research revealed that elderly men were $42.5 \%$ less likely to report poor health status than elderly women and that this is in keeping with the literature.

In a study of the elderly in Latin America and Caribbean countries, self reported health status shows large intercountry variability and more muted heterogeneity due to gender and age [42]. The authors found that women and the very old are more likely to declare themselves in bad health. In addition, the mean number of self reported chronic conditions increases with age and is higher for females than it is for males. In this study, the prevalent rate of chronic diseases was $31 \%$. This is less than the $80 \%$ reported in a study in Trinidad [39]. The main chronic illnesses reported by the respondents in this study were hypertension, diabetes and arthritis. This is in keeping with the study by Rawlins et al. [39] and other Caribbean studies on this age group [43, 44]. Furthermore, a study conducted on elderly Jamaicans showed that this age cohort was mainly affected by chronic non-communicable diseases [45]. In 1991, cardiovascular diseases followed by diabetes mellitus and neoplasms were the diseases for which Jamaicans 65 years older were most often hospitalized. Although we did not examine hospitalization data for the current study, interestingly and indirectly the findings somewhat concurs with the 1991 study. The findings in this paper revealed that hypertension is the leading cause of reported disease followed by diabetes mellitus. The 1994 Jamaica Survey of Living Conditions [46] indicates that persons over 60 years old exhibited the highest prevalence of protracted illness. Additionally, $81.5 \%$ of the ill or injured sought medical care from private institutions. Females were more likely than males to seek medical care, and are partially explained in the fact that they were more willing to declare that they were ill and this is the first sign of recognition that there is an ill-health matter that needs to be addressed through medical attention.

Diabetes mellitus is one of the leading causes of morbidity and mortality among persons aged 65 and older [47]. About $20 \%$ of persons in this age group are estimated to have diabetes, with another $25 \%$ in pre-diabetic stages [48]. Moreover, because diabetes can be asymptomatic for many years, about $50 \%$ of older individuals with diabetes are thought to be undiagnosed [49]. In Jamaica, diabetes-related deaths in 1994 had increased $147 \%$ over the 1980 level and represented the third leading cause of loss of years of potential life among women and tenth among men [50]. There is evidence that this is due to the low rates of awareness, treatment and control among patients with hypertension and diabetes [51, 52].

Hypertension was the main non-communicable cause of poor health in the sample, and is more common among women and the elderly in Jamaica [53]. It is known to be a major risk factor for the development of diabetic renal disease, and hyperglycaemia also has a role in the development of diabetic nephropathy [54]. Hypertension is one of the most important treatable causes of morbidity and mortality and accounts for a large proportion of cardiovascular diseases in elderly [55]. Studies from developed countries have reported prevalence of raised blood pressure among elderly to vary from $60 \%$ to $80 \%$ [56].

One of the findings of this study was that married and separated elderly adults have increased odds of reporting poor health. This is not so unexpected given the context of Jamaica where most of the respondents in the sample are from the rural area. Statistics for Jamaica in 2007 showed that the prevalence of rural poverty was $15.3 \%$ which was 2.5 times more than that in urban areas and 3.8 times more than in peri-urban areas [57]. With more elderly Jamaicans residing in rural areas, and poverty being significant higher in those geographical areas, those who are married would have social support from their partners, but would be more economic challenged in providing food and the addition responsibility of medical care on occasions when illness affects them or their partner. Due to their low socioeconomic status coupled with ageing and the possibility of unemployment, they will be highly unlikely to afford and 
access health care as well as to take care of the other spouse. These findings are contrary to other research that has documented a positive relationship between longer life, good health status and marriage which likely can be attributed to the heightened financial well-being that accompanies being married [58]. In addition to possibly low socio-economic status, elders who are separated may require more help than those who are married.

Another finding is that the number of men in a household has significantly lower odds of reporting health care. In Jamaica some men have greater economic stability based on their level of employment, income and material resources, which is significantly greater than women. This means that these men are more likely to have accumulated more in their working years than women. This increased their ability to provide for themselves and their household in later life. Ageing is a rural phenomenon in Jamaica as more elderly resides there. Furthermore, there is a sub-culture in rural areas that men are the head of the household and are responsible to work, while a woman's responsibilities include the rearing of children and household domestication. Hence, households with more men have a greater probability of more economic resources than those with more women. Although the sub-culture in rural areas is that men's responsibility is for financial resources, this is not dominant in urban areas. Men are paid more than women and may have access to more financial resources. This then explains the finding for why more elderly men in a household being an advantage to that dwelling than one with more women as they have the capacity to absorb the financial challenges in later life.

One indicator that can be used to evaluate how people are responding (or not responding) to life's challenges is their psychological state. According to Diener [59], there is a correlation between one's psychological state and subjective wellbeing; this suggests that psychological conditions influence health status. Diener and Emmons [60] refined psychological conditions into negative and positive affective psychological conditions and argued that each plays a different role in affecting wellbeing. They opined that being optimistic about life direct influences wellbeing, and negative emotions and pessimism affect one's wellbeing indirectly. This was concurred in a later finding that showed the significant direct association between happiness (ie positive affective condition) and subjective wellbeing [61]. Lyubomirsky [61] identified 'comfortable income', 'robust health', supportive marriage', and 'lack of tragedy' or 'trauma' in the lives of people as factors that distinguish happy from unhappy people, which was earlier noted in a study by Diener, Suh, Lucas and Smith [62]. Negative and positive affective conditions based on those scholars do influence subjective wellbeing differently, and so must be taken into consideration in the study of health status. The current study concurs with the literature as it found a direct correlation between negative affective psychological conditions and poor health status, and an inverse significant association with positive affective conditions and poor health status. Interestingly, the study revealed that the strength of both phenomena was stronger for positive than negative affective condition. Embedded therein is how positive conditions will significant reverse poor health status of the elderly and the decreasing role of negative conditions on health status.

\section{CONCLUSION}

The life expectancy of Jamaicans is increasing and the gender gap has widened in recent years. Majority of the respondents in the sample had good health, and those with poor health status were more likely to report having hypertension followed by diabetes mellitus. High mortality rates for avoidable and preventable diseases and potential years of life lost are major public health concerns, especially for regional health planners and healthcare providers. These diseases are often considered to be a manifestation of lifestyle choices, though it must be recognized that choices are greatly affected by social, cultural and economic factors. The prevalence of chronic diseases and levels of disability in older people can be reduced with appropriate health promotion and strategies to prevent non-communicable diseases. This research provides valuable information on mortality and health status which can help planners to specifically and adequately address the health needs of the elderly in Jamaica.

\section{REFERENCES}

[1] Pelaez M. Building the foundations for health in old age in the Americas. Rev Panam Salud Publica / Pan Am J Public Health 2005; 17: 299-302.

[2] Commission for Latin America and the Caribbean (ECLAC)/ Caribbean Development and Cooperation Committee (CDCC). Population ageing in the Caribbean: an inventory of policies, programmes and future challenges. Port of Spain: Trinidad and Tobago 2004.

[3] Palloni A, Wyrick R. Mortality decline in Latin America: Changes in the structures of causes of deaths, 1950-1975. Soc Biol 1981; 28: 187-216.

[4] Preston SH. Mortality patterns in national populations with special reference to recorded causes of death. New York: Academic Press 1976.

[5] Crimmins, E, Hayward M, Saito Y. Differentials in active life expectancy in the older population of the United States. J Gerontol: Soc Sci 1996; 51B: S111-20.

[6] Palloni A, Pinto-Agiurre C, Pelaez M. Demographic and health conditions of ageing in Latin America and the Caribbean. Int $\mathrm{J}$ Epidemiol 2002; 31: 762-71.

[7] Liu X, Hermalin, Yi-Li-Chuang. The effect of education on mortality among older Taiwanese and its pathways. J Gerontol: Soc Sci 1998; 53B: S71-82.

[8] Statistics Canada. Health Reports, 1997; 9(1): 1. Ottawa, USA: Bureau of the Census 1998.

[9] Young ME. World Health Organization (2003). World Health Report. Shaping the future. Health problems and policies for older women: An emerging issue in developing countries. World Bank: Human Resources Development and Operations Policy (HRO). Geneva: Working Papers 1994.

[10] Murray CL, Lopez A, Eds. The Global Burden of Disease, World Health Organization, Geneva, 1996.

[11] Ubink-Veltmaat LJ, Bilo HJG, Groenier KH, Houweling ST, Rischen RO, Meyboom-de Jong B. Prevalence, incidence and mortality of type 2 diabetes mellitus revisited: a prospective population-based study in The Netherlands (ZODIAC-1). Eur J Epidemiol 2003; 18: 793-800.

[12] Wild S, Sicree R, Roglic G, King H, Green A. Global prevalence of diabetes: estimates for the year 2000 and projections for 2030. Diabetes Care 2004; 27: 1047-53.

[13] Wilson P, Anderson K, Kannel W. Epidemiology of diabetes mellitus in the elderly. The Framingham study. Am J Med 1986; 80(Suppl. 5a): 3-9.

[14] Gu K, Cowie C, Harris M. Mortality in adults with and without diabetes in a national cohort of the U.S. population, 1971-1993. Diabetes Care 1998; 21: 1138-45. 
[15] Damsgaard EM, Froland A, Mogensen CE. Over-mortality as related to age and gender in patients with established non-insulindependent diabetes mellitus. J Diabetes Complic 1997; 11: 77-82.

[16] Sasaki A, Uehara M, Horiuchi N, Hasegawa K, Shimizu T. A 15year follow up study of patients with non-insulin-dependent diabetes mellitus (NIDDM) in Osaka, Japan. Factors predictive of the prognosis of diabetic patients. Diabetes Res Clin Pract 1997; 36: 41-7.

[17] Rogers RG. The effects of family composition, health and social support linkage on mortality. J Health Soc Behav 1996; 37: 326-8.

[18] Braithwaite S. The elderly in Barbados: problems and policies. Bull Pan Am Health Org 1990; 24: 314-29.

[19] Manton MKG, Stallard E, Tolley HD. Limits to human life expectancy: evidence, prospects, and implications. Popul Dev Rev 1991; 17: 603-37.

[20] Suzman RM, Willis DP, Manton KG, Eds. The Oldest Old. New York: Oxford University Press 1992.

[21] Eldemire D. An epidemiological study of the Jamaican elderly. $\mathrm{PhD}$ Thesis. Jamaica: The University of the West Indies, Jamaica, 1993.

[22] Plan of Action on Health and Ageing. Older Adults in the Americas 1992-2000. Washington: PAHO 1999.

[23] Statistical Institute of Jamaica. Demographic Statistics, 2007. Kingston: STATIN 2008.

[24] Desai P, Hanna B, Melville B, Wint B. Infant mortality rates in three parishes of western Jamaica, 1980. West lndian Med J 1983; 32: 83-7.

[25] McCaw-Binns A, Fox K, Foster-Williams K, Ashley DE, Irons B. Registration of births, stillbirths and infant deaths in Jamaica. Int $\mathrm{J}$ Epidemiol 1996; 25: 807-13.

[26] Mathers C, Ma Fat D, Inoue M, Rao C. Counting the dead and what they died form: An assessment of the global status of cause of death data. Bull World Health Organiz March 2005; 83: 172-3.

[27] Homer D, Lemeshow S. Applied Logistic Regression, $2^{\text {nd }}$ ed. New York: John Wiley \& Sons Inc 2000

[28] Cohen L, Holliday M. Statistics for Social Sciences. London, England: Harper and Row 1982.

[29] Pan Organization Health Organization. Health in the Americas. Older Population and Health Systems: A Profile of Jamaica. Washington DC: PAHO 1998.

[30] Clarke E. Population trends and challenges in Jamaica. J Aging Emerg Econ 2009; 1: 24-32

[31] Medvedev AZ. Negative trends in life expectancy in the USSR, 1964 - 1983. Gerontologist 1985; 25: 201-8.

[32] Myers G. Cross-national trends in mortality rate among the elderly. Gerontologist 1978; 18: 441-8.

[33] Population ageing in the Caribbean: longevity and quality of life. LC/CAR/L.26, December 2004. www.monitoringris.org/documents/ tools_reg/uneclac1.pdf

[34] Smith J. Measuring health and economic status of older adults in developing countries. Gerontologist 1994; 34: 491-6.

[35] Idler EL, Benjamin Y. Self-rated health and mortality: a review of twenty-seven community studies. J Health Soc Behav 1997; 38: 2137.

[36] Iddler EL, Kasl S. Self-ratings of health: Do they also predict change in functional ability? J Gerontol 1995; 50B: S344-S53.

[37] Schechter S, Beatty P, Willis GB. Asking Survey Respondents about Health Status: Judgment and Response Issues. In: Schwarz N, Park D, Knauper B, Sudman S, Eds. Cognition, Aging, and SelfReports. Ann Arbor, Michigan: Taylor and Francis 1998.

[38] Luteijn B. Health status of the elderly in the Marigot Health District, Dominica. West Ind Med J 1996; 45(Suppl 2): 31

[39] Rawlins JM, Simeon DT, Ramdath DD, Chadee DD. The elderly in Trinidad: Health, social and economic status and issues of loneliness. West Indian Med J 2008; 57: 589-95.
[40] Benyamini Y, Idler E. Community studies reporting association between self-rated health and mortality: additional studies, 1995 to 1998. Res Aging 1999; 21: 392-401.

[41] Lebrão ML, Duarte YAO, organizadores. SABE - Saúde, BemEstar e Envelhecimento: oprojecto SABE no Municipio de Sao Paulo: uma abordagem inicia Brasilia (DF): projeto SABE no Município de Sao Paulo: uma abordagem inicial. Brasília (DF): Organização Pan-Americana da Saude; 2003. Disponivel em. http://www.opas.org.br/sistema/arquivos/l_saber.pdf

[42] Palloni A, McEniry G. Aging and health status of elderly in Latin America and Caribbean: Preliminary findings. J Cross Cult Gerontol 2007; 22: 263-85.

[43] Eldemire D. Ageing the reality. In Morgan, Owen, Health Issues in the Caribbean. UWI Press, Jamaica 2005; Chap 2: pp. 157-77.

[44] Alberts JF, Koopmans POC, Gerstenbluth I, Van der Heuvel WJ. The health profile of Curacao: results from the Curacoa health study. West Ind Med J 1995; 44(Supp1 2): 21-2.

[45] World Health Organization. Regional Core Health Data System: Country Profile - Jamaica; 2001. http://www.Documents and Settingsluser|Desktop $\backslash$ Regional Core Health Data System Country Profile JAMAICA.mht.

[46] Planning Institute of Jamaica, Statistical Institute of Jamaica. Jamaica Survey of Living Conditions (JSLC), 1994. Kingston: Planning Institute of Jamaica, Statistical Institute of Jamaica 1995.

[47] Desai M, Zhang P, Hennessy C. Surveillance for morbidity and mortality among older adults - United States 1995- 1996. MMWR: Morb Mortal Wkly Rep 1999; 48: 7- 25.

[48] Samos L, Roos B. Diabetes mellitus in older persons. Med Clin North Am 1998; 82: 791-803.

[49] Meneilly G, Tessier D. Diabetes in elderly adults. J Gerontol Series A: Biol Sci Med Sci 2001; 56A: M5- M13.

[50] Health Situation Trends. Situation Trends. Health in the Americas. Washington, D.C.: PAHO 1988; Vol. 1 (Scientific Publication \# 569).

[51] Wilks R, Sargent LA, Guilliford MC, Reid M, Forrester T. Quality of care of hypertension in three clinical settings in Jamaica. West Indian Med J 2000; 49: 220-5.

[52] Wilks RJ, Sargent LA, Guilliford MC, Reid ME, Forrester TE. Management of diabetes mellitus in three settings in Jamaica. Rev Panam Salud Publica 2001; 9: 65-72.

[53] Sargeant L, Boyne M, Bennett F, Forrester T, Cooper R, Wilks R. Impaired glucose regulation in adults in Jamaica: who should have the oral glucose tolerance test. Pan Am J Pub Health 2004; 16: 3542 .

[54] Wald H, Markowitz H, Zevin S, Popovtzer MM. Opposite effects of diabetes on nephrotoxic and ischemic acute tubular necrosis. Proc Soc Exp Biol Med 1990; 195: 51-6.

[55] Hypertension Study Group. Prevalence, awareness, treatment and control of hypertension among the elderly in Bangladesh and India: a multicentric study. Bull World Health Organ 2001; 79: 490-500.

[56] Kalavathy MC, Thankappan KR, Sharma PS, Vasan RS. Prevalence, awareness, treatment and control of hypertension in an elderly community-based sample in Kerala, India. Nat Med J India 2000; 13: 9-15.

[57] Planning Institute of Jamaica, Statistical Institute of Jamaica. Jamaica Survey of Living Conditions (JSLC), 2006. Kingston: Planning Institute of Jamaica, Statistical Institute of Jamaica 2007.

[58] Lillard, L, Waite L. Til death do us part: marital disruption and mortality. Am J Soc 1995; 100: 1131-56.

[59] Diener E. Subjective wellbeing. Psychol Bull 1984; 95:542-75.

[60] Diener E, Emmons RA. The independence of positive and negative affect. J Pers Soc Psychol 1984; 47: 1105-17.

[61] Lyubomirsky S. Why are some people happier than others? The role of cognitive and motivational process in wellbeing. Am Psychol 2001; 56: 239-49.

[62] Diener E, Suh M, Lucas E. Smith H. Subjective well-being: three decades of progress. Psychol Bull 1999; 125: 276-302. 